\title{
A UTILIZAÇÃO DA LIDERANÇA SITUACIONAL COMO DIFERENCIAL ESTRATÉGICO PARA AS ORGANIZAÇÕES CONTEMPORÂNEAS
}

\section{THE UTILIZATION OF SITUATIONAL LEADERSHIP AS A STRATEGIC DIFFERENTIAL FOR CONTEMPORARY ORGANIZATIONS}

\author{
Recebido 15/10/2010 \\ Aceito 16/09/2011
}

Giselle Aparecida Duarte ${ }^{1}$ e Adriana Cássia Papa ${ }^{2}$

RESUMO

Este artigo tem como propósito apresentar os resultados da utilização da Liderança Situacional como diferencial estratégico para as organizações contemporâneas. Desse modo, os temas Motivação no trabalho, Liderança e Empoderamento, Estilos de Liderança e Liderança Situacional foram essenciais para versar acerca da temática. Para tal proposta, a metodologia utilizada foi o estudo de caso, e a coleta dos dados foi realizada a partir das seguintes ferramentas qualitativas: entrevistas semiestruturadas e observação. Esta pesquisa foi realizada na "Empresa X", e os sujeitos escolhidos para este estudo foram os líderes da referida organização. Os resultados obtidos indicaram que, para ser um líder situacional, não é fundamental o conhecimento conceitual sobre o tema; entretanto, é fundamental o alinhamento com as práticas contemporâneas, visto que cabe à liderança o papel de diagnosticar, flexibilizar e estabelecer parceria para o desempenho e desenvolvimento de equipes autodirigidas, de alta performance.

Palavras-chave: Liderança. Liderança Situacional. Empoderamento. Motivação.

Especialista em Gestão Estratégica de Pessoas (SENAC-MG). Graduada em Psicologia.E-mail: psicologi@hotmail.com Mestre em Administração (SENAC-MG). Graduada em Psicologia. E-mail: apapa@terra.com.br 


\section{ABSTRACT}

This article had the purpose of presenting the results for the use of Situational Leadership as a strategic differential at Contemporary Organizations. The themes Motivation in the workplace, Leadership and Empowerment, Styles of Leaderships and Situational Leadership were essential to debate the proposed topic. Having said this, the methodology applied here was case study and data collection was made with the use of the following qualitative tools: semi-structured interviews and observation. The present research was conducted at "Company X" and the individuals chosen for the study were leaders from this mentioned organization. The results obtained seem to indicate that in order to be a situational leader it is not fundamental to have conceptual knowledge of the topic. However, it is essential that this is aligned with contemporary practices. It is a leader's responsibility to diagnosticate, make it flexible and to establish partnership to improve performance and to develop self-directed teams of high performance.

Keywords: Leadership. Situational Leadership. Empowerment. Motivation.

\section{INTRODUÇÃO}

As atuais exigências do mercado apontam para a necessidade de profissionais com múltiplas competências. Os líderes hoje desempenham um papel fundamental na eficácia dos grupos e das organizações, sendo, muitas vezes, sinalizadores do sucesso ou fracasso organizacional.

Nesse cenário de incertezas e mudanças frequentes, é importante que os líderes sejam hábeis em adaptar-se, acompanhando as novas tendências do mercado se quiserem ter seu lugar ao sol. De acordo com Moura e Torres (2009, p. 11), "diante das incertezas desse cenário os líderes devem ser capazes de adotar novos modelos mentais, percebendo que as mudanças ocorrem em escala contínua, decorrentes de demandas situacionais internas e externas".

A Liderança Situacional é uma proposta de mudança da teoria tradicional hierarquizada, condizente com o contexto atual, a era do conhecimento. Na contemporaneidade, já não é mais possível manter os velhos padrões, pois o mundo corporativo busca mais e mais a competitividade e efetividade. É imprescindível que o líder contemporâneo consiga identificar e diagnosticar situações complexas, que esteja apto a trabalhar em equipe, que conheça o negócio e saiba a quem recorrer nas situações adversas.

Nesse sentido, a Liderança Situacional enfatiza a capacidade do líder em reconhecer o nível de maturidade de seu liderado e adequar o estilo de liderança ao nível de desenvolvimento, sendo uma estratégia bastante competitiva (BLANCHARD et al., 2007).

O papel do líder situacional é contribuir com os colaboradores no que for preciso, seja na direção, no treinamento, no apoio ou nas metas. E estes poderão aperfeiçoar suas habilidades, sua motivação e sua autoestima, ou seja, o objetivo das ações do líder é criar condições para que as pessoas se tornem cada vez mais autodigiridas e automotivadas.

É a partir do "desenvolvimento de indivíduos e de equipes autodirigidas, que substituam a hierarquia, que gerentes podem assumir com maior facilidade seus novos, e mais influentes, papéis como incentivadores, mentores e líderes de equipe." (BLANCHARD et al., 2007, p. 92).

A Liderança Situacional, nas organizações, suscita colaboradores e clientes mais satisfeitos, clima organizacional mais harmônico, produtividade e, consequentemente, aumento da lucratividade. 
Para Blanchard et al. (2007), o líder situacional eficaz detém três habilidades fundamentais: diagnóstico, flexibilidade e parceria para o desempenho. Nenhuma dessas habilidades é particularmente difícil, na verdade demandam somente prática. Então, desenvolver essas habilidades não corresponde, necessariamente, a conhecer ou dominar o conceito de Liderança Situacional, e é possível que líderes que desconheçam seu significado teórico apresentem características de Liderança Situacional.

Assim, ante ao exposto, torna-se pertinente questionar: os líderes da "Empresa X" revelam características da Liderança Situacional, ainda que não conheçam com maior profundidade esse conceito?

Para responder a essa questão, este artigo está assim subdividido, além desta introdução, apresentará uma estrutura conceitual sobre motivação no trabalho, liderança, liderança e empoderamento, estilos de liderança e liderança situacional. Em seguida, a metodologia e as apresentações e a análise dos resultados. As considerações finais serão elaboradas a partir da análise dos resultados e de ponderações relevantes ao trabalho proposto.

\section{MOTIVAÇÃO NO TRABALHO}

As organizações têm hoje uma preocupação recorrente com a motivação de seus profissionais. Desse modo, muitas vêm desenvolvendo programas de incentivos e formas diversas de estimular seus colaboradores. Sendo assim, Bergamini (1999, p. 35) enfatiza que "a motivação é uma energia, uma tensão, uma força, uma pressão, mas não tem papel ativo no direcionamento do comportamento", ou seja, a motivação é uma disposição para a ação, entretanto não garante a trajetória que o comportamento percorrerá.

Sob essa perspectiva, faz-se relevante pontuar como os profissionais contemporâneos, "enquadrados" na teoria X e Y, de Douglas McGregor (1960), direcionam-se no que tange à motivação. Na teoria X, McGregor (1960) considera que a maioria das pessoas necessitam de uma supervisão rigorosa e, muitas vezes, precisam ser ameaçadas com punições para cumprir com seus deveres; buscam segurança e não lhes interessa a responsabilidade; as vantagens são os ganhos financeiros e regalias profissionais. Já na teoria $Y$, o profissional adquire cada vez maior autodomínio e autonomia; o apoio do gestor está relacionado à busca do desenvolvimento e ao processo de amadurecimento do subordinado, pois, com esta atuação do líder, os ganhos são mais abrangentes para todos os envolvidos no processo.

Entretanto, também se faz necessário, para melhor compreensão do tema motivação no trabalho, destacar a leitura que David McClelland e Burham (1997) apresentam. Os autores discorrem sobre a teoria das necessidades socialmente adquiridas e destacam que há três necessidades básicas fundamentais para a motivação, quais sejam: a necessidade de realização, de poder e de afiliação. Na primeira, os profissionais têm desejo de realizar-se - esta é a motivação - e, inicialmente, focam em seu crescimento pessoal e em desenvolver suas habilidades, sem a participação de outros. Depois, anseiam receber retorno sobre sua performance, ou seja, como estão sendo vistos, e buscam a excelência. Acerca da necessidade de poder, o foco é em exercer influência sobre as pessoas e seus comportamentos; o desejo de estar no comando é maior do que o de legitimar a eficiência de seu trabalho. Na terceira e última necessidade, a de afiliação, o indivíduo aspira obter relacionamentos interpessoais agradáveis, busca a afeição e a cooperação, e a relação estabelecida está acima das tarefas (McCLELLAND; BURHAM, 1997).

Outro autor relevante nesta discussão é Herzberg (1966), que desenvolveu uma teoria denominada Teoria dos Dois Fatores (fatores de higiene e fatores de motivação). "Os fatores de 
higiene dizem respeito a como as pessoas são tratadas para que sua insatisfação seja mantida em grau mínimo" (BERGAMINI, 1999, p. 77). É possível concluir que fatores de higiene estão relacionados às condições físicas e ambientais em que se encontra o colaborador. Esses fatores, para Herzberg, não são suficientes para resultar em motivação, pois quando bem tratados pela organização implicam, exclusivamente, não causar a insatisfação.

Já "os fatores motivacionais estão ligados ao uso que a organização faz da energia motivacional de cada colaborador" (BERGAMINI, 1999, p. 77). São fatores inteiramente ligados às tarefas ou ao trabalho propriamente dito e têm relação direta com os resultados e a produtividade dos profissionais.

Portanto, Herzberg enfatiza que a motivação deriva do trabalho, e é a partir da evolução no cargo/tarefa que o colaborador terá oportunidade de desenvolver-se profissional e psicologicamente. Nesse sentido, a percepção do líder sobre o momento em que está o liderado é um ponto fundamental para o desenvolvimento deste e de seu empoderamento, caso este colaborador tenha autonomia para a realização de suas atividades. Assim, é possível salientar que a teoria apontada por Herzberg (1966) é correlata à teoria X e Y, de McGregor (1960), e à das necessidades socialmente adquiridas, de McClelland e Burham (1997), pois "a motivação concebida como algo interior às pessoas passa a exigir líderes com grande sensibilidade interpessoal, [...] mas principalmente pessoas que se importem em conhecer em profundidade o seu seguidor" (BERGAMINI, 1999, p. 90). Logo, um líder sensível reconhecerá as habilidades e limitações de seu colaborador e poderá interferir positivamente em seu desenvolvimento e influenciar em sua motivação, ou seja, em sua ação na equipe, na qualidade e assertividade da entrega dos resultados necessários à organização.

Assim, faz-se a aposta que a motivação deriva do modo como os colaboradores são vistos e tratados pela empresa em âmbito geral, seja no estilo da liderança adotada, nas exigências relativas ao seu cargo ou no reconhecimento de seu trabalho.

\section{LIDERANÇA: ALGUNS CONCEITOS}

No contexto atual, a liderança é assunto amplamente tratado, seja em artigos, revistas ou em fontes diversas. Segundo Pinto (2005) apud Moura e Torres (2009, p. 18), "o tema liderança tem despertado o interesse de inúmeros estudiosos". Sendo este um assunto instigante, é relevante perguntar: o que significa liderança?

Para Tannenbaum, Weschler e Massarik (1972, p. 42), liderança é "a influência interpessoal exercida numa situação, por intermédio do processo de comunicação, para que seja atingida uma meta ou metas especificadas". Já Chiavenato (2004, p. 448) define-a como "uma influência interpessoal em uma dada situação e dirigida através do processo de comunicação humana para a consecução de um ou mais objetivos específicos".

Ante ao exposto, percebe-se que os autores destacam a liderança como a capacidade do líder de influenciar um grupo em prol de determinado objetivo, ou seja, trata-se da habilidade de atrair seus liderados para que estes estejam motivados a atingir e superar os resultados.

Para Blanchard et al. (2007, p. 15), liderança é a "capacidade de influenciar os outros a liberar seu poder e potencial de forma a impactar o bem maior". Essa definição está relacionada à observação de que a liderança não está atrelada somente a resultados, pois "[...] não deve ser exercida apenas por um ganho pessoal ou para atingir objetivos, deve ser um propósito muito maior" (BLANCHARD et al., 2007, p. 15). Segundo Blanchard et al. (2007), este objetivo maior é denominado visão arrebatadora, ou seja, uma empresa que está em conformidade com sua 
missão, visão, valores, propósitos e credibilidade, tanto de seus colaboradores quanto de seus clientes.

Bennis e Nanus (1988, p. 15) afirmam que os líderes "são aqueles que delegam poder aos empregados, a fim de que eles procurem novas formas de atuar". Já para Ramos (1989, p. 146), o líder é "um agente capaz de facilitar o desenvolvimento de iniciativas livremente geradas pelos indivíduos, passíveis de se amalgamarem sob a forma de configurações reais".

Acompanhando essa reflexão, o gestor pode utilizar como aliado no desenvolvimento de pessoas o empoderamento. Com este recurso estratégico, poderá promover "maior motivação" aos colaboradores e propiciar concomitante autonomia e amadurecimento à sua equipe. No caso de um profissional com o perfil da teoria $X$, que precisa de maior direcionamento e rigor, e, no caso do profissional da teoria $Y$, que desenvolve com eficiência e segurança, a ação do líder será proporcional à necessidade de cada um, pois é fundamental que este trate cada membro de sua equipe de forma singular, visto que as pessoas são diferentes e possuem subjetividades diferentes. É a partir desta consideração que a aplicabilidade da Liderança Situacional, tema deste artigo, terá resultados ou não. Sendo assim, o "ideal" é que o líder tenha como objetivo construir uma equipe de alta performance, na qual líderes e liderados possam caminhar juntos com a autogestão, para alcançar os resultados traçados pela organização que representam.

Portanto, o líder situacional acompanha seus liderados, identificando a curva de aprendizagem, ou seja, o estágio evolutivo de cada profissional que compõe sua equipe e deve oferecer maior ou menor autonomia a estes, de acordo com a resposta de cada colaborador que faz parte da referida equipe. Contudo, o mais importante é incentivar e preparar seus colaboradores para uma atuação de autoliderança e empoderamento, através do desenvolvimento contínuo deles.

\section{LIDERANÇA E EMPODERAMENTO}

O empoderamento pode ser considerado um fator de motivação das equipes. Blanchard et al. (2007, p. 88) definem empoderamento como "O processo de liberar o poder que existe nas pessoas - seu conhecimento, suas experiências e sua motivação - e direcionar esse poder para alcançar resultados positivos para a organização."

Então, nesse processo, é possível compreender que empoderamento é permitir que os colaboradores utilizem seu poder, conhecimentos, habilidades e motivação em busca de transpor as limitações e conquistar os objetivos. O empoderamento corresponde a conceder ao colaborador maior autonomia, mas, ao mesmo tempo, maior responsabilidade. Suas ações serão pautadas em seus conhecimentos, habilidades e experiências, e o líder acompanhará esse percurso.

Em organizações bem administradas, os líderes estão cientes dos resultados positivos, frutos do empoderamento dos colaboradores, pois estes resultados "simplesmente não são possíveis quando toda a autoridade está concentrada no topo da hierarquia e a gerência assume toda a responsabilidade pelo sucesso" (BLANCHARD et al., 2007, p. 87).

Blanchard et al. (2007) afirmam que o empoderamento, na vida real, funciona e que pesquisadores divulgaram que colaboradores empoderados resultam em melhorias no aspecto integral para as empresas. Segundo Malone (1997) apud Blanchard et al. (2007, p. 90), "o empoderamento é essencial para empresas que desejam ser bem-sucedidas em uma nova economia baseada no conhecimento." 
Os líderes que buscam criar uma cultura empoderada em sua organização "devem recorrer a três chaves: compartilhar informações, especificar quais são os limites e substituir a velha hierarquia por pessoas e equipes autodirigidas" (BLANCHARD et al., 2007, p. 95).

Ao compartilhar as informações, o líder propicia ao grupo credibilidade, e daí inicia-se um processo de parceria. Os colaboradores sentem-se mais animados a dar sugestões significativas na resolução de problemas e também a compartilhar o aprendizado organizacional, "aprender a partir da informação e aplicar o que se aprendeu a novas situações" (BLANCHARD et al., 2007, p. 98).

Especificar os limites significa deixar claro ao colaborador até que ponto chegou seu desenvolvimento e o que será a sua responsabilidade. "As pessoas também recebem treinamento e desenvolvem as habilidades necessárias para que possam ter maior autonomia" (BLANCHARD et al., 2007, p. 100).

Ao substituir a velha hierarquia por equipes e pessoas autodirigidas, os gestores terão maior oportunidade e tempo de desenvolver "seus novos e mais influentes papéis como incentivadores, mentores e líderes de equipe" (BLANCHARD et al., 2007, p. 92).

Portanto, o empoderamento, nas organizações, pode gerar resultados que são diferenciados da hierarquização tradicional. Seus efeitos são notórios, os colaboradores se sentem mais reconhecidos e apresentam melhor desempenho, isto reflete na produtividade do negócio e ainda possibilita a dedicação e o maior foco do gestor aos papéis de liderança.

\section{ESTILOS DE LIDERANÇA}

As teorias sobre os estilos de liderança revelam que, de acordo com o comportamento adotado pelo líder, a ênfase será na tarefa a ser desenvolvida ou no colaborador, podendo ser contrabalançada. Há também o estilo de liderança que indica omissão tanto com relação às tarefas quanto aos colaboradores. Para melhor compreensão desses conceitos, faz-se necessária uma breve explanação sobre os três principais estilos de liderança.

Na liderança democrática, também chamada de participativa ou consultiva, o líder aprova a participação dos membros da equipe e ocupa-se tanto com o trabalho quanto com a equipe. Nesse sentido, o líder se torna um facilitador do grupo. "No estilo democrático os programas podem ser discutidos pelo grupo e este pode chegar a decisões" (HERSEY; BLANCHARD, 1977, p. 90). Então, o líder está aberto à discussão do planejamento, estabelecendo uma parceria com os liderados que, por sua vez, respondem com produtividade e qualidade superior e ainda satisfação, responsabilidade e comprometimento. Neste estilo de liderança, os colaboradores se sentem mais motivados e confiantes em sugerir melhorias e ser responsáveis por suas atividades, já que seu líder os apoia.

Já na liderança autocrática, a postura do líder é diferente. Nesta liderança, também chamada de diretiva ou autoritária, o foco é na tarefa. "No estilo autoritário todos os programas são estabelecidos pelo líder" (HERSEY; BLANCHARD, 1977, p. 90), logo o líder autocrático planeja sem a participação do grupo e decide as técnicas para a execução do serviço. Além disso, determina qual a tarefa de cada subordinado e também quem será o parceiro de trabalho de cada liderado. Por adotar uma postura dominadora, provoca tensão e frustração no grupo. De modo geral, o trabalho só é realizado mediante a presença do líder, que é temido pelo grupo, e, ao ausentar-se, a tendência deste grupo é reduzir sua produtividade.

Em contrapartida, no estilo liberal, o líder não se preocupa nem com as tarefas nem com os liderados. O líder liberal ou laissez faire não impõe regras ao grupo, e este, por sua vez, não 
o respeita. Neste estilo de liderança, as decisões, divisão de tarefas e/ou planejamento são feitos pelos liderados, já que o líder participa de forma mínima. "Este estilo de comportamento permite que os membros do grupo façam o que desejam fazer. Não se estabelecem programas ou processos" (HERSEY; BLANCHARD, 1977, p. 91). A tendência destes membros é de acreditar que têm autonomia de ação, e, muitas vezes, pode surgir a vontade de desistir, pois não sentem que podem contar com o líder nos momentos cruciais.

Nos três estilos de liderança, é possível notar a mudança de enfoque: "a liderança autocrática põe forte ênfase no líder, enquanto a liderança liberal põe forte ênfase nos subordinados. A liderança democrática põe ênfase tanto no líder como nos subordinados" (CHIAVENATO, 1993, p. 140). Logo, a aplicabilidade do estilo de liderança influenciará o processo do trabalho e seu resultado final, e este poderá ser um fator motivador da equipe.

\section{LIDERANÇA SITUACIONAL}

As perspectivas atuais do mercado evidenciam que, para as organizações se manterem competitivas, elas precisam não só de uma boa estrutura física; é importante valorizar e investir no capital humano. No passado, não era dada à classe trabalhadora a oportunidade de contribuir para o sucesso da empresa. Este modelo resultou em várias críticas, como, por exemplo, o filme Tempos Modernos, de Charles Chaplin.

A liderança deve estar alinhada às necessidades e habilidades dos colaboradores, para que o líder possa lançar mão deste importante diferencial competitivo que é a força das equipes. "Para que uma pessoa seja incentivada a dar o melhor de si, a liderança deve se adequar ao nível de desenvolvimento em que essa pessoa se encontra" (BLANCHARD et al., 2007, p. 110). O líder deve buscar o melhor estilo, conforme a exigência da situação. Desta tática de combinar o nível de desenvolvimento ao estilo de liderança, surgiu o conceito de Liderança Situacional.

Spricigo (1999, p. 48), ao refletir sobre a Liderança Situacional, destaca que "está implícita a ideia de que o líder deve ajudar os liderados a amadurecer até o ponto em que sejam capazes e estejam dispostos a fazê-lo". Silva e Kovaleski (2006, p. 2) definem que

O fator chave na Liderança Situacional é a necessidade do líder desenvolver sua sensibilidade e percepção, diagnosticando sua equipe para que possa definir como irá se comportar, pois em qualquer situação em que uma equipe possa estar, a liderança sempre deverá realizar suas funções básicas de gerir com atenção concentrada nos objetivos e resultados. (SILVA; KOVALESKI, 2006, p. 2).

Tanto Spricigo (1999) quanto Silva e Kovaleski (2006) ressaltam a importância da sensibilidade e percepção do líder diante de seus liderados, auxiliando-os em suas dificuldades e apoiando seu crescimento. Blanchard et al. (2007) ressaltam o mesmo aspecto em sua definição: a Liderança Situacional ${ }^{\circledR} \|^{3}$ se baseia na crença de que as pessoas podem e querem crescer e de que não existe um estilo de liderança que seja considerado o melhor para encorajar esse crescimento. A aplicação do estilo de liderança deve ser feita sob medida para a situação.

${ }^{3}$ Em 1986, foi criado, por Ken Blanchard e Paul Hersey, o modelo de Liderança Situacional. Após constatações de que alguns aspectos essenciais do modelo não estavam sendo validados na prática por milhares de usuários e não eram compatíveis com as pesquisas sobre desenvolvimento de equipes, Ken e os fundadores das empresas Ken Blanchard criaram um modelo revisado e denominaram liderança situacional ${ }^{\circledR}$ II (BLANCHARD et al., 2007). 
Para Blanchard et al. (2007), os colaboradores devem ser tratados de formas diferentes, pois cada um encontra-se em um estágio evolutivo e necessita de determinada ação de seu líder para alcançar novos progressos. Utilizando-se desta lógica, foi criado o "Modelo da Liderança Situacional ${ }^{\circledR}$ II", que pode ser observado na figura 1, a seguir:

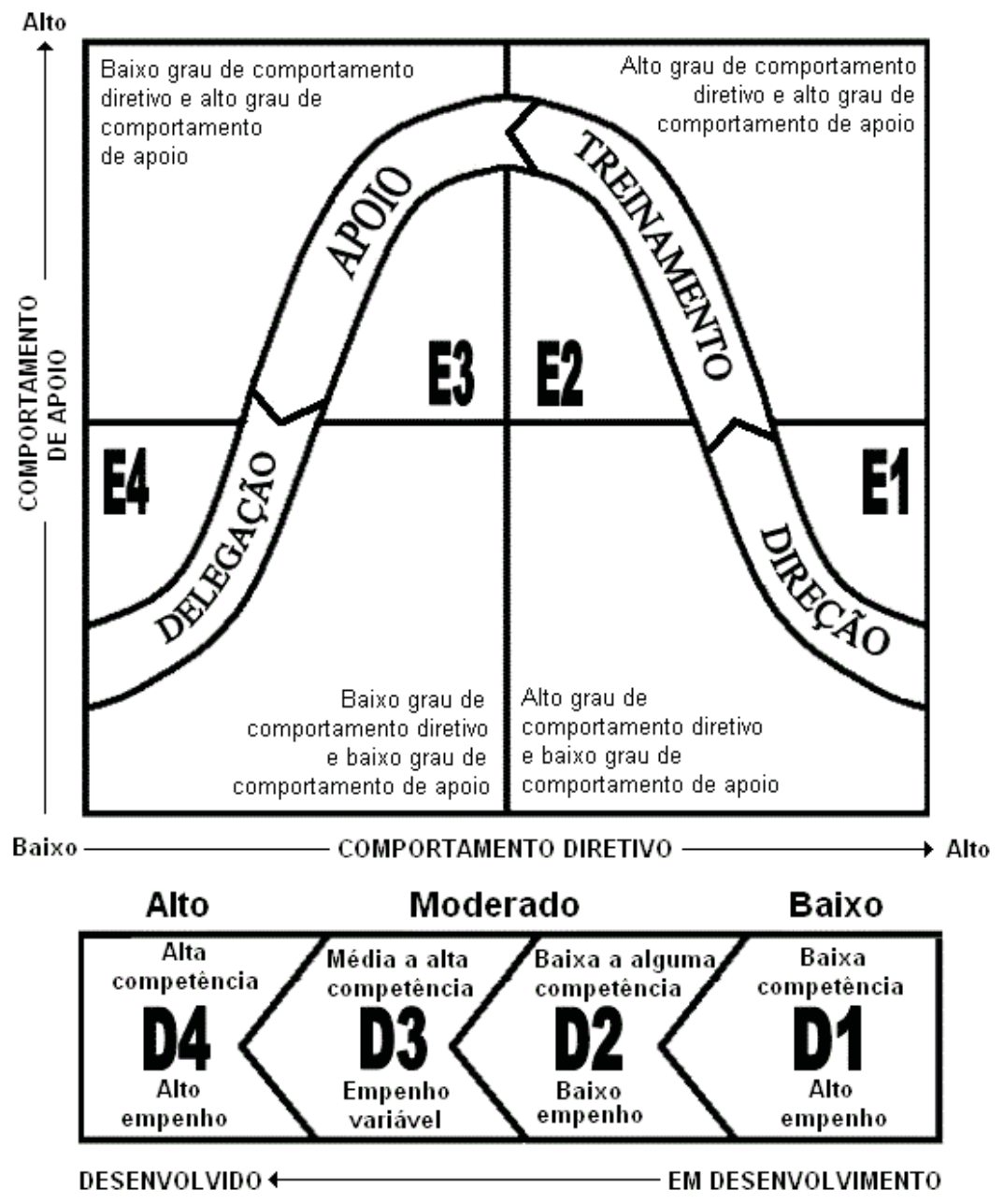

Nivel de Desenvolvimento do(s) Colaborador(es)

Figura 1 - O Modelo de Liderança Situacional ${ }^{\circledR}$ II Fonte: BLANCHARD et al. (2007).

O autor faz uma proposição de como adequar o estilo de liderança ao nível de desenvolvimento. Considerando a figura 1, no modelo de Liderança Situacional, há quatro estilos básicos de liderança, que correspondem a quatro níveis básicos de desenvolvimento. Sendo assim, para o estágio nomeado principiante empolgado, que apresenta baixa competência e alto empenho, é importante o estilo de direção; para o nível de desenvolvimento denominado aprendiz decepcionado, que evidencia baixa alguma competência e baixo empenho, é importante o estilo de treinamento. Já para um colaborador considerado capaz, mas cauteloso, ou seja, que apresenta competência de moderada a alta e empenho variável, o estilo adequado é o de apoio. Para o perfil realizador autoconfiante, que revela alta competência e alto empenho, o adequado é delegar (BLANCHARD et al., 2007). 
Assim, para o profissional denominado principiante empolgado, é importante que o líder apresente todos os processos e procedimentos da empresa, as características peculiares a seu trabalho. Dessa forma, a motivação deste colaborador, somada aos conhecimentos e habilidades adquiridas, farão com que ele caminhe para um novo nível de desenvolvimento.

No estágio aprendiz decepcionado, o colaborador compreende os objetivos de seu trabalho, no entanto os considera mais difíceis do que ele imaginava. O líder, então, deve utilizar-se do estilo de liderança de treinamento, dirigindo e supervisionando suas atividades. Além disso, deve também elogiá-lo e encorajá-lo a tomar a iniciativa, ainda que as decisões finais sejam do líder, já que o colaborador ainda está no processo de aprendizado (BLANCHARD et al., 2007).

Quando o colaborador já domina os processos, é competente, porém apresenta algumas incertezas sobre sua capacidade, ou seja, é um colaborador capaz, mas cauteloso, o líder deve adotar o estilo de apoio, reconhecer "seus esforços, ouvir suas preocupações e sugestões" (BLANCHARD et al., 2007, p. 114).

Já no caso de realizadores autoconfiantes, ou seja, colaboradores que dominam os processos, revelam pró-atividade e têm autoconfiança, o estilo de delegação é o apropriado. A função do líder, nesse momento, "é empoderá-lo dando-lhe autonomia e demonstrando confiança na sua habilidade de agir de modo independente. É necessário reconhecer seu excelente desempenho." (BLANCHARD et al., 2007, p. 114-115).

Ao avaliar esses estágios de desenvolvimento, há uma observação importante: "O nível de desenvolvimento varia de meta para meta e de tarefa para tarefa. Um Indivíduo pode estar em um nível de desenvolvimento quanto a uma meta ou tarefa e em outro nível quando se trata de outra meta ou tarefa" (BLANCHARD et al., 2007, p. 115). Então, é importante estar atento a este detalhe, que é fundamental no sucesso da aplicação do modelo da Liderança Situacional ${ }^{\circledR}$ II.

Ao entender a estrutura da Liderança Situacional ${ }^{\circledR}$ II, é possível compreender que, para tornar-se eficaz em seu uso, é necessário que o líder domine três habilidades: diagnóstico, flexibilidade e parceria para o desempenho. "Nenhuma dessas habilidades é particularmente difícil; cada uma delas requer apenas prática" (BLANCHARD et al., 2007, p. 120).

A habilidade de diagnóstico requer do líder a percepção da competência de seu liderado, ou seja, seus conhecimentos, habilidades, atitudes e seu empenho para o alcance dos objetivos. Assim que o líder sentir-se confortável em converter, facilmente, os estilos de liderança, conforme a demanda, "já dominou a segunda habilidade de um líder situacional: flexibilidade" (BLANCHARD et al., 2007, p. 121).

A terceira e última habilidade é uma parceria para o desempenho, na qual o líder contará com seu colaborador; "é uma parceria que envolve confiança mútua entre duas pessoas que trabalham juntas para alcançar metas em comum" (BLANCHARD et al., 2007, p. 139).

Portanto, a Liderança Situacional aponta para um estilo de liderança mais conveniente para o desenvolvimento e, também, indica a probabilidade de sucesso de acordo com a capacidade do líder de diagnosticar, flexibilizar e estabelecer parceria para o desempenho. A Liderança Situacional é um modelo que pode ser aplicado em diversos contextos sociais, porém foi tratado apenas em âmbito organizacional devido ao foco deste estudo. 


\section{METODOLOGIA}

O método de pesquisa adotado foi o estudo de caso, que "é uma estratégia de pesquisa que busca examinar um fenômeno contemporâneo dentro do seu contexto" (YIN apud ROESCH, 1999, p. 155). Além disso, "é especialmente adequado ao estudo de processos e explora fenômenos com base em vários ângulos" (ROESCH, 1999, p. 197).

A organização pesquisada, objeto de estudo deste caso, é uma empresa de médio porte, privada, que possui cerca de 65 colaboradores, especializada no segmento de telecomunicações e que recebe aqui o nome fictício de "Empresa X". Essa empresa atua no mercado mineiro há 19 anos, e sua matriz está localizada em Belo Horizonte.

Foram utilizadas, nesta pesquisa, as seguintes ferramentas qualitativas para a coleta de dados: a entrevista semiestruturada e a observação. A observação, segundo Roesch (1999), é um instrumento que complementa a coleta de dados, oportunizando a aquisição das informações, avaliação, fatos e objetos a pesquisar.

A entrevista semiestruturada foi escolhida devido ao fato de propiciar flexibilidade e aprofundamento, permitindo ao entrevistador explorar as questões, de modo a ir ao encontro dos aspectos mais relevantes para esta pesquisa. De acordo com Roesch (1999), "O grau de estruturação duma entrevista em uma pesquisa qualitativa depende do propósito do entrevistador. Em entrevistas semiestruturadas utilizam-se questões abertas, que permitem ao entrevistado entender e captar a perspectiva dos participantes da pesquisa." (ROESCH, 1999, p. 159).

As entrevistas foram baseadas em um roteiro, fundamentado na teoria da Liderança Situacional, no intuito de avaliar a questão que norteia esta pesquisa, ou seja, os líderes da "Empresa X" revelam características da Liderança Situacional, ainda que não conheçam com maior profundidade esse conceito?

Na primeira parte, constam os dados pessoais dos entrevistados, como formação, experiência profissional, cargo atual, dentre outros. Para a segunda parte, foram formuladas 14 questões, que investigam o conhecimento dos entrevistados sobre a Liderança Situacional e a prática destes líderes no cotidiano.

Desta pesquisa, participaram nove sujeitos, sendo estes os gestores das seguintes áreas: Recursos Humanos (RH), Administração, Logística, Comércio, Serviços, Manutenção, Instalação e Finanças.

Na sala de Recursos Humanos, foram realizadas as entrevistas com os líderes, que, posteriormente, foram transcritas, com base no roteiro orientador. Após a coleta, os dados foram organizados e analisados, através da interpretação e inferência sistemática dos conteúdos (BARDIN, 2002), com o propósito de apreciar a proposta de trabalho deste artigo.

\section{APRESENTAÇÃO E ANÁLISE DOS RESULTADOS}

A partir das entrevistas realizadas na "Empresa X", é possível perceber que os gestores não dominavam o conceito de Liderança Situacional. Um dos entrevistados definiu e caracterizou outro estilo de liderança, não relacionado a esta. Dois preferiram não arriscar sobre o que se tratava. Seis definiram o conceito a partir da dedução, aproximando-se do real significado. Contemplando tais resultados, foi possível perceber que esse é um conceito simples, no qual pessoas que não o conheçam podem, facilmente, identificá-lo e, inclusive, praticá-lo. 
A característica unânime com relação às habilidades que os líderes devem ter foi a habilidade no relacionamento interpessoal, destacando que o estabelecimento de um bom relacionamento favorece maior confiança dos membros no líder e vice-versa (BLANCHARD et al., 2007). Foram apontadas também características como: respeito, troca de conhecimento, feedback, identificação das potencialidades e valorização dos talentos.

A maior parte dos entrevistados, ou seja, oito respondentes, veem-se como flexíveis, abertos à discussão e às sugestões, objetivam explorar, conforme foi citado por um dos líderes, "o que cada um tem de melhor", buscam entender suas dificuldades e estabelecer uma relação de confiança com os seus colaboradores. Tais características são correlatas às citadas por Blanchard et al. (2007) como essenciais ao líder situacional.

Foi revelado, através da entrevista, que os líderes percebem a necessidade de tratar os colaboradores de acordo com o momento em que eles se encontram, ou seja, levar em conta o nível de desenvolvimento do profissional, suas habilidades, e basear-se nisso para então decidir que tipo de postura é a mais indicada. Tal reflexão encontra-se pautada nos fundamentos da Liderança Situacional, de Blanchard et al. (2007), os quais salientam que, além de o líder utilizar sua capacidade diagnóstica para identificar o estágio no qual o colaborador está, ele "deve ser flexível o suficiente para variar seu estilo de liderança, dependendo do nível de habilidade de seu pessoal, pois, de outro modo, sua eficácia será limitada" (BLANCHARD et al., 2007, p. 120).

Desse modo, é importante mencionar que a empresa pesquisada está passando por um processo de reestruturação. Neste processo, os gestores estão trabalhando junto ao $\mathrm{RH}$, com a implantação de novas tendências dos modelos de gestão de pessoas, com intuito de construir uma gestão mais estratégica, visto que há uma grande preocupação na formação e no desenvolvimento das lideranças, para alcançar maior vantagem competitiva e manutenção de um clima organizacional positivo.

Os entrevistados ressaltaram a importância de um trabalho um pouco mais focado em indicadores. Todos os respondentes apontaram para a necessidade de maior foco em treinamento, tanto técnico quanto comportamental, sendo o último requisitado por todos os líderes e indicado como um dos próximos passos a desenvolver. Dos entrevistados, seis levantaram como ponto chave para o êxito da reestruturação a melhoria da comunicação geral, principalmente com relação à marcação de reuniões e circulação das informações internas como um todo. Para Blanchard et al. (2007), quando há o compartilhamento das informações, ocorre o processo de parceria, pois este procedimento, além de confiança entre os membros do grupo e na organização, propicia a disseminação do conhecimento, incentivando a troca de ideias, questionamentos e discussões.

Analisando as entrevistas a partir do modelo de Liderança Situacional $®$ II, de Blanchard et al. (2007), de como adequar o estilo de liderança ao nível de desenvolvimento, os resultados da pesquisa revelaram diversos aspectos: primeiro, com relação aos principiantes empolgados, os entrevistados enfatizaram a importância de dar direcionamento aos novos colaboradores, ensinando-os como são as etapas dos processos e acompanhando-os de perto, para perceber quais são suas dificuldades. Utilizaram o termo treinamento no sentido de ensinar os procedimentos, direcionar, acompanhar, "[...] explicar sobre a rotina da empresa, [...] falar sobre a cultura", "[...] ponto a ponto", até que eles sejam capazes de realizar as tarefas "[...] sem ficarem perdidos", enfatizaram os entrevistados. Nesse aspecto, há a concordância com a literatura, que aponta que, para colaboradores que iniciam suas atividades na organização e mostramse empenhados, o melhor é aplicar o estilo de direção (BLANCHARD et al., 2007).

Quanto aos aprendizes decepcionados, os respondentes acreditam ser necessário realizar um treinamento, no qual irão rever e realinhar os processos, acompanhá-los de perto, 
conversar, identificar a origem da insegurança e trabalhá-la, transmitindo confiança e apoiando-os. As afirmações dos entrevistados correspondem à teoria de Blanchard et al. (2007), que aponta a necessidade de adotar o estilo de treinamento, continuando a dirigir e supervisionar de perto as atividades dos colaboradores, propondo-se a conversar, dando conselhos e ouvindo as perguntas e sugestões.

Para os colaboradores capazes, mas cautelosos, os respondentes apontaram como importante motivá-los, incentivá-los, mostrar do que o colaborador é capaz, inclusive valendo-se dos indicadores. Alguns dos entrevistados utilizaram expressões como: "mostrar para ele que $O$ trabalho dele é eficaz", "Conversar, dar apoio, dar suporte, não deixar o cara sozinho". Assim, os respondentes evidenciam a importância do estilo de apoio no qual o colaborador é estimulado a refletir e é encorajado a assumir riscos, pois já adquiriu tal competência (BLANCHARD et al., 2007).

Já com realizadores autoconfiantes, os entrevistados evidenciaram que o melhor, neste caso, é delegar, estabelecer com o colaborador em questão um tipo de parceria, ouvindo suas sugestões e avaliando sua aplicabilidade, ou seja, utilizar suas habilidades para "ele ser um multiplicador". De acordo com um dos entrevistados, o colaborador "seria um parceiro estratégico", um "divisor de tarefas". Os respondentes ressaltaram, também, a importância de motivar esse tipo de comportamento, estando aberto às sugestões e promovendo o reconhecimento. Um dos respondentes apontou como fundamental "[...] estar atento, olhar com bastante cuidado, colocar novos desafios", para, assim, não desanimar o colaborador e ele continuar a desenvolver-se. Nesse sentido, Blanchard et al. (2007) sinalizam que convém deixar que o colaborador seja responsável por conduzir seu próprio trabalho. A função do líder é empoderá-lo e demonstrar confiança na sua habilidade de agir de modo independente (BLANCHARD et al., 2007).

Ao serem questionados sobre a alternativa adequada no caso de colaboradores que precisam desenvolver tanto habilidades técnicas quanto comportamentais, foi unânime a indicação do treinamento como melhor instrumento para desenvolver estes aspectos.

As características apontadas no arcabouço teórico a respeito da Liderança Situacional foram destacadas a partir das entrevistas. Assim, considerando as três habilidades de um líder situacional e os quatro estilos básicos de liderança no modelo de Liderança Situacional ${ }^{\circledR}$ II, de Blanchard et al. (2007), os resultados da pesquisa revelam que, na "Empresa X", há líderes que apresentam características da Liderança Situacional, ainda que não conheçam, com maior profundidade, o conceito.

Portanto, ante ao exposto, pode-se afirmar que, apesar de não haver conhecimento conceitual aprofundado sobre o tema Liderança Situacional e suas peculiaridades, os líderes da "Empresa X" são capazes de adotar suas características e, ao utilizar esta importante ferramenta estratégica, eles possibilitam a si e aos colaboradores um clima mais harmonioso, que suscita alto desempenho, do qual a organização desfrutará.

\section{CONSIDERAÇÕES FINAIS}

Considerando o cenário atual, no qual as organizações vivenciam intensas mudanças, tanto nos contextos social, econômico, político e cultural, é fundamental que o líder contemporâneo seja capaz de se adaptar a esta realidade e valorizar não só os resultados, mas também os relacionamentos no ambiente corporativo. 
Contemplando esse cenário, este artigo teve o propósito de expor os resultados da utilização da Liderança Situacional como diferencial estratégico para as organizações contemporâneas, contextualizando sua prática, a partir do problema: os líderes da "Empresa X" revelam características da Liderança Situacional, ainda que não conheçam com maior profundidade esse conceito?

Através dessa proposta, foi possível perceber, na "Empresa X", que os gestores apresentaram características da Liderança Situacional, ou seja, são capazes de avaliar o nível de desenvolvimento de seus profissionais e ajustar o melhor estilo de liderança, de acordo com a situação, empregando o modelo proposto por Blanchard et al. (2007) no cotidiano.

Pode-se destacar que, no caso da "Empresa X", o fato de os líderes estarem atentos ao ritmo e à curva de aprendizagem dos liderados proporciona um maior desenvolvimento a estes profissionais. O que deve ser incentivado é o exercício diário de diagnosticar, flexibilizar e estabelecer parceria para o desempenho da equipe, o que poderá agregar valor tanto para os profissionais quanto para a organização.

Além disso, verificou-se que, para aplicar o modelo de Liderança Situacional na organização, não é essencial que o líder detenha conhecimento teórico aprofundado sobre o tema. Dessa forma, o gestor que estiver alinhado às tendências de mercado, mantiver o foco em resultados e, principalmente, perceber a importância do capital intelectual para as empresas terá grandes probabilidades de ser um líder com características da Liderança Situacional, conforme evidenciado por meio dos resultados obtidos.

Nesse sentido, o desenvolvimento de um "líder situacional" não depende, a priori, dos conhecimentos teóricos acerca do tema em questão, mas pode ser uma realidade alcançada a partir da prática; prática esta embasada no investimento do suposto líder no autoconhecimento e autodesenvolvimento, conforme foi constatado na "Empresa X" e destacado no arcabouço teórico.

A leitura da teoria e prática apresentadas demonstra que a Era do Conhecimento coloca em evidência a necessidade de ações criativas e inovadoras, onde o recurso de ferramentas estratégicas, como a Liderança Situacional, torna-se um diferencial competitivo no alcance dos resultados esperados tanto para o negócio quanto para as pessoas que fazem parte da dinâmica de uma organização.

Nessa reflexão, é interessante pontuar que aos líderes da atualidade cabe um papel mais estratégico, utilizando suas competências, habilidades e atitudes em prol de uma organização com medidas mais consistentes e coerentes, onde pessoas e organização possam caminhar juntas. Tal laço resulta em colaboradores e clientes satisfeitos e em um clima organizacional agradável. Diante disso, cabe afirmar que a consequência da Liderança Situacional é a geração de bons frutos, ou melhor, bons gestores, o que impactará, diretamente, nos resultados da empresa.

Entretanto, um aspecto a ser ressaltado é que a Liderança Situacional ainda é um tema incipiente, sobre o qual grande parte das produções se restringe à compreensão do que se trata. Contudo, este estudo não teve a intenção de esgotar a temática, mas ampliar as discussões e sugerir novas perspectivas de pesquisa, à luz do instigante tema, ou seja, da liderança situacional como um diferencial estratégico para as organizações contemporâneas. 


\section{REFERÊNCIAS BIBLIOGRÁFICAS}

BARDIN, L. Análise de conteúdo. Tradução de Luís Antero Reto e Augusto Pinheiro. Lisboa: Edições 70, 2002.

BENNIS, W.; NANUS, B. Líderes: estratégias para assumir a verdadeira liderança. São Paulo: Harbra, 1988.

BENNIS, W. G. A invenção de uma vida: reflexões sobre liderança e mudanças. Tradução de Renata Silva Cardoso. Rio de Janeiro: Campus, 1999.

BERGAMINI, C. W.; CODA, R. (Org.). Psicodinâmica da vida organizacional: motivação e liderança. 2. ed. São Paulo: Atlas, 1999.

BLANCHARD, K. et al. Liderança de alto nível: como criar e liderar organizações de alto desempenho. Tradução de Rosalia Neuman Garcia. Porto Alegre: Bookman, 2007.

CHIAVENATO, I. Introdução à teoria geral da administração. Ed. Compacta. Rio de Janeiro: Elsevier, 2004.

. Gerenciando pessoas: o passo decisivo para a administração participativa. São Paulo: McGraws-Hill; Makron Books do Brasil, 1993.

HERSEY, P.; BLANCHARD, K. H. Psicologia para administradores de empresas. São Paulo: EPU, 1977.

Psicologia para administradores:

a teoria e as técnicas da liderança situacional. 4. ed. São Paulo: EPU, 1986.

HERZBERG, F. Work ond nature of fran. Cleveland, Ohio: The Norld Publishing, 1966.

McCLELLAND, D. C.; BURHAM, D. H. O poder é o grande motivador. In: VROOM, V. H. (Org.). Gestão de pessoas, não de pessoal. Rio de Janeiro: Campus, 1997.

McGREGOR, D. The human side of interprise. New York: McGraw-Hill, 1960.
MOURA, M. R.; TORRES, P. B. Contribuições da liderança situacional para as organizações. 2009. 89 f. Monografia (Especialização em Gestão de Pessoas) - Programa de Pós-Graduação do Laboratório de Tecnologia, Gestão de Negócios e Meio Ambiente, Escola de Engenharia, Universidade Federal Fluminense, Niterói, 2009.

PONTIFÍCIA UNIVERSIDADE CATÓLICA DE MINAS GERAIS. Pró-Reitoria de Graduação. Sistema de Bibliotecas. Padrão PUC Minas de normalização: normas da ABNT para apresentação de artigos de periódicos científicos. Belo Horizonte, 2008. Disponível em: < http:/ /www.pucminas.br/ biblioteca/>. Acesso em: 15 dez. 2009.

RAMOS, A. G. A nova ciência das organizações: uma reconceituação da riqueza das nações. Rio de Janeiro: FGV, 1989.

ROESCH, S. M. A. Projetos de estágios e de pesquisa em administração: guia para estágios, trabalhos de conclusão, dissertações e estudo de caso. São Paulo: Atlas, 1999.

SILVA, U. B.; KOVALESKI, J. L. Desenvolvimento de equipe através da liderança situacional e feedback $360^{\circ}$ : caso de uma equipe de manutenção da Copel Distribuição S.A., Superintendência de Distribuição Centro-sul. In: ENCONTRO NACIONAL DE ENGENHARIA DE PRODUÇÃO, 26., 2006, Fortaleza. Anais... Rio de Janeiro: ABEPRO, 2006.

SPRICIGO, M. J. Desenvolvimento de habilidades operacionais: uma proposta de gestão do conhecimento operacional. 1999. 102 f. Dissertação (Mestrado) - Universidade Federal de Santa Catarina, Florianópolis, 1999.

TANNENBAUM, R.; WESCHLER, I. R.; MASSARIK, F. Liderança e organização: uma abordagem de ciência do comportamento. São Paulo: Atlas, 1972.

YIN, R. K. The case study crisis: some answers. Administrative Science Quarterly, Cornell University, v. 26, Mar. 1981. 